\title{
"No consienta que el encomendero nos obligue a servicios personales ni nos maltrate". Violencia y castigos infrajudiciales en un Pueblo de indios riojano, fines del siglo XVII
}

(4) Marisol García"

Fecha de recepción: 16 de junio de 2020. Fecha de aceptación: 30 de septiembre de 2020

Palabras clave

relaciones interétnicas castigos

pueblos de indios Gobernación del Tucumán

\section{Resumen}

Este artículo analiza los castigos y malos tratos que reciben los indígenas del Pueblo de Guaco -La Rioja, Gobernación del Tucumán, Virreinato del Perú- a fines del siglo XVII, desde un corpus documental compuesto por un juicio y la Visita de Luján de Vargas. Para determinar la legitimidad de los castigos aplicados se examinará la legislación y las normativas vigentes para los Pueblos de indios, junto a los testimonios indígenas y del encomendero. Se mostrará que la violencia era utilizada como mecanismo de coacción infrajudicial por la potestad de ciertos cargos, en un contexto donde seguían vigentes prácticas de servicio personal. Luego, se buscará captar el imaginario hispano-criollo subyacente en estos ejercicios coercitivos, observando qué es lo que teme o quiere impedir el estamento dominante a través de la violencia y el amedrentamiento. Finalmente, se reflexionará sobre las múltiples dimensiones que poseen los castigos y se mencionarán algunas estrategias indígenas para denunciarlos.

"Do not allow that the encomendero forces us to personal services or mistreats $u s^{\prime \prime}$. Infrajudicial violence and punishments in an Indian village in La Rioja, late seventeenth century

\section{Abstract}

Key words

interethnic relationships punishments

Indian villages Tucuman Province
This article examines the punishments and mistreatments that the Indigenous people of Guaco -La Rioja, Tucumán Province, Viceroyalty of Peru- suffered at late $17^{\text {th }}$ century, from a trial and the Inspection of Luján de Vargas. In order to determine if these punishments were legitimate, we will examine the legislation of the Indian villages and several Indian testimonies found in colonial 
files. This paper will show that the power of certain offices used violence as a mechanism of infrajudicial coercion, in a context where practices of personal service still prevailed. Then, we will analyse the Hispanic-Creole imaginary that underlies these punishments, observing what the dominant establishment fears and wants to prevent through violence and intimidation. Finally, we will reflect on the multiple dimensions of punishments and mention some of the indigenous strategies to denounce them.

\section{Introducción}

Este artículo busca contribuir al campo de estudio de las relaciones interétnicas coloniales, examinando el rol de la violencia como parte central de la relación de dominio. Su objetivo principal es analizar los ejercicios coercitivos que reciben los indígenas del Pueblo de Guaco -La Rioja, Gobernación del Tucumán- ${ }^{1}$ a fines del siglo XVII. Dentro de este concepto incluyo a los castigos corporales, malos tratamientos, amedrentamientos y apremios que fueron ejercidos hacia la población indígena con el objetivo de condicionar su comportamiento y someterla a la voluntad del ejecutor. Para ello, se examinará la legislación y las normativas vigentes, reparando en quiénes tenían facultades para castigar los delitos, faltas y malos comportamientos dentro de los Pueblos de indios. Se buscará determinar si los castigos aplicados fueron legítimos o si, por el contrario, no debieron ser ejecutados, entendiéndolos como actos extrajudiciales de violencia y abuso por la potestad de ciertos cargos.

Estos ejercicios coercitivos se relevarán en dos contextos particulares y desde fuentes específicas. La primera es un expediente judicial proveniente del Archivo Histórico de la Provincia de Córdoba (AHPC) por las tierras donde estaban asentados los indígenas. Entre 1674 a 1690 se desarrollan varios pleitos por la estancia de Guaco, tratados tanto en tribunales locales de la Gobernación del Tucumán como en la Audiencia de La Plata de los Charcas. ${ }^{2}$ En ellos participan activamente las autoridades étnicas de los malfines y andalgalás, persiguiendo distintos fines (García, 2018).

La segunda fuente es la visita del oidor Luján de Vargas a las encomiendas de La Rioja y Catamarca (1692-1693). Esta documentación presenta distintas situaciones donde la violencia es utilizada cotidianamente como amedrentamiento, represalia y castigo. La riqueza de esta fuente para abordar la violencia interétnica fue advertida y trabajada por numerosos autores (entre ellos, Bixio, 2007; González Navarro y Grana, 2013; Conti, 2019). No obstante, al analizar conjuntamente la visita y el juicio se logra un abordaje más completo de la problemática, ampliando la escala de estudio y triangulando la información.

El presente trabajo se organiza de la siguiente manera. El primer apartado expone de forma general el rol de los castigos en la sociedad colonial americana, como sistema de disciplinamiento dentro del marco del pluralismo jurídico que diferenciaba las penas según la calidad de la persona. Haciendo foco en la población indígena, se examinará la legislación que regulaba los castigos y malos tratamientos, reparando en su condición de miserables. Luego, pasando al contexto de la Gobernación del Tucumán, se mencionarán las normativas locales y los procesos de administración de las penas. Se tomará el concepto de infrajusticia para caracterizar las prácticas de control social que escapan del ámbito de las autoridades competentes y se ejercen de manera autónoma, principalmente por los encomenderos. Hacia el final se presentará la situación
1. La Gobernación del Tucumán, dependiente en lo político del Virreinato del Perú y en lo judicial de la Audiencia de Charcas, comprendió el extenso territorio hoy ocupado por las provincias argentinas de Jujuy, Salta, Tucumán, Catamarca, La Rioja, Santiago del Estero y Córdoba.

2. Este conflicto judicial está dividido en varios expedientes del AHPC y del Archivo y Biblioteca Nacionales de Bolivia (ABNB). Las citas de este artículo solo pertenecen a uno de los expedientes del AHPC, no obstante, la comprensión del caso, sus actores sociales y motivaciones se logró con la lectura completa de todo el corpus de documentación disponible y en base a los trabajos de Lorandi y Sosa Miatello (1991) y García (2018 y en prensa). 
de los Pueblos de indios y encomiendas riojanas, así como otras investigaciones que analizaron distintas situaciones de violencia en la Gobernación.

En el segundo apartado se introducirá el caso de análisis, observando el papel de la violencia en el juicio por la estancia de Guaco. Se analizarán los castigos ilegítimos y amedrentamientos que reciben el mandón Francisco Gualcusa, y el indio Juan Apotaan en la persecución de sus intereses. Además, se presentarán algunas de las estrategias que esgrimen los indígenas para acusar a los responsables, como acudir a la Audiencia de Charcas, lejos de las redes de poder locales, y buscar apoyo en indígenas de otros Pueblos.

En tercer lugar, se analizarán las denuncias indígenas presentadas al visitador Luján de Vargas sobre los castigos y malos tratos perpetuados por su encomendero. Se estudiará luego su desagravio, observando cómo justifica, atenúa o niega el accionar violento y punitivo. Terminando el apartado, se mencionarán otras prácticas que aparecen en la Visita que, aunque no involucran castigos físicos, son violentas y dan cuenta de la situación desigual de poder y de explotación.

En el cuarto y último apartado se buscará captar el imaginario hispano-criollo que subyace a los castigos indígenas, pensando qué teme o quiere evitar el sector dominante, encarnado en la figura del encomendero. Para ello, se volverá sobre las presentaciones judiciales y el desagravio del encomendero, observando cómo en su argumentación construye los hechos sancionables y defiende el uso de la violencia.

Siguiendo las tendencias ya estudiadas para la Gobernación del Tucumán, se mostrará que en el caso analizado los indígenas no habían cometido delitos o faltas graves que ameritaran los castigos corporales ejercidos por el encomendero, sin tener las competencias para ello. La violencia era utilizada como mecanismo de coacción infrajudicial por la potestad de ciertos cargos. Su objetivo principal era lograr el ajuste de los nativos al sistema colonial, maximizando su explotación económica en un contexto donde ciertas prácticas de servicio personal seguían vigentes a pesar de su ilegalidad.

\section{Los castigos hacia la población indígena y su rol en la Gobernación del Tucumán}

La violencia, entendida como el empleo arbitrario de la fuerza contra el otro (Torres Arancivia, 2016: 84), formaba parte del sistema de gobierno impuesto por la monarquía hispana en sus colonias americanas. Una de sus múltiples formas de expresión eran los castigos físicos. Tal es así que Tomás y Valiente (1969) propone que la principal herramienta política del absolutismo fue el monopolio de impartir penas, basadas mayormente en el escarmiento corporal y en los castigos públicos ejemplares. ${ }^{3}$ Foucault, retomando la teoría clásica de la soberanía, sostiene que el poder del monarca recae precisamente en la posibilidad de hacer morir (Foucault, 1996). Dado que el soberano no podía controlar a todos sus súbditos de manera directa utilizaba castigos corporales ejemplares, sumamente dolorosos, para alertar a la población y disuadirla de quebrantar las normas y las leyes.

Gobernar a través del terror, por medio de la tortura judicial, fue la práctica política rectora, legitimada ideológicamente por fundamentos de la teología moral (Tomás y Valiente, 1969; Torres Arancivia, 2016; Quarlieri, 2018). ${ }^{4}$ Desde

\footnotetext{
3. Las penas de aflicción, como los castigos corporales, se distinguen de otro tipo de penas como las capitales, pecuniarias y de infamia

4. El papel de la Iglesia católica en la difusión de las penas, el suplicio y el castigo como formas efectivas de control de la vida social fue central para la institución de este régimen punitivo. Pecado y delito conformaron dos fenómenos indisociables durante la colonia hasta la secularización del derecho penal (Clavero, 1990; Araya, 2006).
} 
el pensamiento católico el cuerpo fue considerado corruptible e inestable, susceptible a la tentación y obstaculizando tanto la racionalidad como la espiritualidad " $\mathrm{y}$, de este modo, solo las disciplinas, normas y reglas permitirán lograr su transformación en camino o medio para la salvación, es decir, su control, domesticación y subordinación" (Araya, 2006: 365). Esta lógica de mortificación corporal está inserta en un sistema patriarcal, donde los varones adultos son los encargados de la rectitud de sus mujeres, hijos, indios y esclavos a cargo. En este contexto, los castigos actuaban como un correctivo y tenían una función pedagógica: lograr que cada uno ejecutara el rol esperado.

Siguiendo a Angeli (2014), en esta sociedad la idea central consistía en conservar y garantizar el orden natural establecido por Dios. Como la sociedad americana colonial era estamental, donde la pureza de la sangre determinaba distintas calidades de personas, el equilibrio se lograba dando a cada uno lo suyo. "La coexistencia de distintos ordenamientos jurídicos fue denominada 'pluralismo jurídico'. Existían, por tanto, diferentes conjuntos de normas, de diversas legitimidades y contenidos, todos ellos insertos en un mismo espacio social" (Angeli, 2014: 125). Sintetizando, había tantas justicias y castigos como estamentos, respetando y reactualizando el lugar que los sujetos ocupaban en el orden colonial (Levaggi, 1975; Clavero, 1986). ${ }^{5}$

Los castigos corporales más frecuentes que recibían los indígenas eran los golpes, los azotes, la inmovilización mediante grilletes y el cepo, el corte de cabellos, la privación de la libertad en prisiones y presidios y, en los casos más extremos, la amputación de algún miembro o la pena de muerte (Levaggi, 1975; Bixio, 2003; Torres Arancivia, 2016). Si bien los castigos físicos estaban contemplados en la legislación, no cualquiera podía impartirlos. En los territorios americanos, la administración de la justicia civil y de las penas legítimas se encontraba delegada y subdividida. Se estructuró a partir de una jerarquía de autoridades jurisdiccionales (Ots Capdequi, 1941; Agüero, 2011). ${ }^{6}$ En la Gobernación del Tucumán la justicia debía ser administrada primeramente por los miembros de la corporación capitular, o por los tenientes de gobernador (Bixio, 2003; González Navarro y Grana, 2013). ${ }^{7}$

Aunque los castigos ejemplares fueron utilizados para controlar a la población, la legislación indiana refleja la voluntad de la corona de proteger a los indígenas de brutales castigos, muchas veces injustificados, de los encomenderos y funcionarios coloniales (Cebreiros-Álvarez, 2004; Aranda Mendiáz, 2006). Tras las atrocidades cometidas en la etapa inicial de conquista, las leyes establecen que los indios no son esclavos sino vasallos libres y en 1542 se prohíbe el servicio personal, régimen por el cual eran sometidos a un sinfín de prestaciones compulsivas, siendo reemplazado por el tributo tasado (Ots Capdequi, 1941: 29). Ordenan a las Audiencias "tener muy especial cuidado del buen tratamiento de los indios y conservación de ellos" ${ }^{8}$ y que no se cometan excesos. Asimismo, establecen que los delitos contra ellos sean castigados con mayor rigor que contra los españoles ${ }^{9}$ y consideran que de cometer ellos algún delito o falta deben recibir penas moderadas, salvo que hayan sido delitos atroces, con malicia o agraviando a otros (Levaggi, 1975; Cebreiros-Álvarez, 2004).

Esto se debe a que, desde el punto de vista legal, los indígenas americanos eran considerados miserables. Esta condición jurídica era compartida con otros desprotegidos de la sociedad española, como pobres, viudas y huérfanos (Ots Capdequi, 1941; Cebreiros-Álvarez, 2004; Hespanha, 2011). Se les aplicó un sistema protector que les permitió abreviar los procesos judiciales, reducir o eliminar su costo y recibir asesoramiento legal con honorarios reducidos o sin
5. Esto se aprecia claramente en el caso de los azotes: "para los esclavos de origen africano estaba estipulada, en las leyes, la máxima cantidad de azotes, tras lo cual se ubicaban los mestizos y luego los indígenas de los pueblos, insistiéndose en que los caciques no fueran castigados de la misma forma para mantener las distinciones. Asimismo, existía una diferenciación en su cantidad y modalidad, en relación a la parte del cuerpo implicada, cuando los azotes eran impartidos sobre el cuerpo de hombres o el de mujeres" (Quarlieri, 2018: 242).

6. En primera instancia intervenían los Alcaldes Ordinarios y Regidores de los Cabildos Municipales, después los Corregidores, luego los Alcaldes Mayores, los Gobernadores, siguen los Capitanes Generales, luego las audiencias y los Virreyes y, por último, el Consejo de Indias o el mismo Rey (Ots Capdequi, 1941).

7. Los puestos capitulares estaban ocupados por miembros de la elite encomendera y terrateniente. De esta forma, desde la justicia local conservaron y aumentaron sus privilegios e intereses, en detrimento del bienestar y autonomía de los demás estamentos, incluidos los indígenas (González Navarro y Grana, 2013).

8. Recopilación de leyes de Indias, lib. $\mathrm{V}$, tit. I, ley 40.

9. Recopilación de leyes de Indias, lib. VI, tit. X, ley 21. 
10. Entre ellas: el servicio en las casas, chacras y viñas del encomendero, la cría de ganado, el recojo de leña, algodón y otros productos, la fabricación de adobe, la limpieza de las acequias, la participación en viajes comerciales, el tejido y el hilado femenino, entre otras (Lorandi, 1988). La producción era dirigida y supervisada directamente por el encomendero o un agente suyo, como un poblero que vivía en el mismo lugar donde se trabajaba, e involucraba a toda la familia indígena, incluidos mayores y niños (Palomeque, 2002: 95-99). Este régimen se caracterizaba por el trabajo continuo y compulsivo, sin remuneración (Boixadós, 2002; Bixio, 2009). ellos (Bixio, 2007). Su supuesta necesidad de amparo llevó al nombramiento de una persona que intercediera por ellos en los juicios e instancias oficiales, como las visitas y desagravios, evitando los abusos que pudieran sufrir: el Protector de Naturales.

Recapitulando, sobre los indígenas de encomienda "pesaba este paternalismo sobre la base de su condición de 'menores perpetuos", 'miserables' y necesitados de un tutor que los condujera hacia las normas de convivencia en orden y policía'" (González Navarro y Grana, 2013: 7). Además del Protector, este rol lo ocupaba el encomendero quien, en nombre de los valores y costumbres cristianas, debía sancionar y reprimir los malos comportamientos de los indígenas a su cargo. Esta sanción se entendía como un correctivo paternal leve que en primera instancia debía ser a través de la palabra, ya que estaba prohibido que los encomenderos castiguen a sus indígenas por iniciativa propia.

Estamos en presencia de un límite aparentemente claro pero que en la práctica se tornaba difuso; esto es, la diferencia entre un mal comportamiento y un delito o falta que correspondía ser tratado por la justicia ordinaria. Teniendo en cuenta esto, podemos diferenciar dos tipos de castigos: los legítimos, ordenados por la justicia siguiendo la normativa y los ilegítimos realizados por mano propia de los encomenderos u otros actores sociales que carecen de las competencias necesarias para asignar y ejecutar un castigo corporal.

En la Gobernación del Tucumán, la legislación protectora de los indígenas fue resistida e incluso contradicha por normativas locales. Las Ordenanzas del Gobernador Abreu de 1576 marcan un hito importante en la historia de las relaciones interétnicas de la región. No solo legalizan el abusivo servicio personal sino que declaran lícito castigar a los indios si no ayudan a sus encomenderos en sus siembras y servicios (Ordenanza N 15) (Lorandi, 1988: 151). El régimen de servicio personal implicaba la entrega de trabajo de los indígenas al encomendero, distribuido en un sinfín de prestaciones (Lorandi, 1988) $\cdot{ }^{10} \mathrm{Al}$ no existir una tasación del tributo, el beneficio obtenido por los encomenderos dependía de la intensidad con que explotaran a la familia indígena, haciendo de la violencia un elemento cotidiano (Lorandi, 1988; Conti, 2019).

Diversos casos presentados por Bixio (2007) y González Navarro y Grana (2013) en Córdoba durante los siglos XVII y XVIII evidencian que el castigo corporal era aplicado de forma tan extendida que algunos encomenderos contaban en sus depósitos con cormas, colleras y potros para castigo de los indios de servicio. Esta práctica frecuentemente sobrepasó la corrección paterna permitida para convertirse en una justicia privada que actuaba al margen de la oficial y que acudía al castigo físico en diversos grados, según la gravedad de la situación o el deseo del encomendero. González Navarro y Grana caracterizan a estas acciones como infrajudiciales por el abuso de poder de los encomenderos y su ejercicio de la violencia sin intervención de las autoridades competentes (2013).

Este concepto fue trabajado por Mantecón Movellán (2002) para referirse a prácticas que escapaban de la administración e instituciones oficiales pero que estaban basadas en valores consuetudinarios, socialmente aceptados. Esta esfera extrajudicial "amparaba prácticas que tenían como finalidad el control de las desviaciones sociales, tanto si constituían un delito como no" (Mantecón Movellán, 2002: 46). Desde la infrajusticia no solo se gestaba el control social sino que se definían los comportamientos tolerables o condenables. 
Este accionar punitivo por parte de los encomenderos hacia los indígenas estaba justificado y, mientras no fuera escandaloso, silenciosamente avalado por la elite y los funcionarios locales. Su objetivo era lograr el ajuste de los nativos al sistema colonial y, consecuentemente, el mantenimiento del orden desigual y jerárquico (Bixio, 2007; González Navarro y Grana, 2013).

El visitador Francisco de Alfaro, alarmado por esta situación generalizada de abusos dentro de la Gobernación del Tucumán, buscó limitar el poder de los encomenderos en sus ordenanzas de 1612, reafirmando la legislación indiana protectora del indígena (Palomeque, 2000; Bixio, 2007). Con ese objetivo prohibió el régimen de servicio personal, tasó y reglamentó los tributos y ordenó la creación de Pueblos de indios o de reducción, caracterizados por el usufructo comunitario de la tierra. Además,

\begin{abstract}
restringió la entrada de estos últimos [los encomenderos] a los pueblos para las épocas de cosecha y siembra y para el cobro de tributo (ord. 32), dispuso que en el interior de los pueblos de indios los alcaldes indígenas aplicarían la justicia hasta penas de 8 azotes (ord. 23), abolió la figura del poblero o mayordomo en las encomiendas por considerarlo un sujeto nefasto y dañoso para los nativos (ord. 29) y prohibió a los encomenderos y a los señores de estancias "castigar por su persona ni mandar castigar ningún yndio de su encomienda o estancia so pena de veinte pesos". Si el castigo aplicado por éstos era "con exçesos" quedaría en manos de la justicia española la aplicación de sanciones (ord. 119) (en González Navarro y Grana, 2013: 8).
\end{abstract}

Con estas medidas Alfaro ratificó que los encomenderos no tenían jurisdicción civil ni criminal sobre los indios, algo que las Leyes de indias habían establecido décadas antes. Es decir que ante un delito o una falta cometida por un indígena sólo debía intervenir la justicia (González Navarro y Grana, 2013). Si la falta era menor, como faltar a la misa o embriagarse ocasionalmente, la sanción la debía aplicar el alcalde de indios, si lo hubiera en el Pueblo.

Es sabido que la aplicación de estas ordenanzas fue sumamente resistida (Palomeque, 2000). ${ }^{11}$ En La Rioja, donde se sitúa el caso de análisis, los encomenderos rechazaron la abolición del servicio personal dilatando la aplicación de las ordenanzas y continuando con sus prácticas abusivas. Según Farberman y Boixadós (2006: 607) bien pudo ser esta la causa del Gran alzamiento diaguita que se desató en 1630. La pacificación posterior y las desnaturalizaciones crearon las condiciones bajo las cuales las reducciones y el nuevo régimen de tributación serian impuestos paulatinamente desde la segunda mitad del siglo XVII.

A fines del siglo XVII Boixadós demuestra que en La Rioja coexistían principalmente dos escenarios (Boixadós, 2002; Boixadós y Zanolli, 2003). Por un lado, había encomiendas radicadas en Pueblos con tierras comunales, compuestas por población diaguita local y algunas etnías desnaturalizadas. La autora utiliza el término encomiendas pueblo para dar cuenta de la situación de algunos de estos grupos, donde la condición de encomienda y Pueblo de indios se superpone -recordemos que el pueblo de indios como lugar de reducción podría albergar a varias encomiendas o grupos indígenas.

Por otro lado, encuentra encomiendas asentadas en tierras de particulares, en las propiedades urbanas o semiurbanas de sus encomenderos. ${ }^{12}$ Estas estaban en peores condiciones ya que carecían de tierras comunitarias, base central para la reproducción autónoma del grupo. Aunque que el tributo -pagado en
11. Por ejemplo, la existencia de reducciones donde funcionaran cabildos indígenas que administraran la justicia en primera instancia no fue constatada para la mayoría de las jurisdicciones, sólo se encuentran referencias aisladas para Jujuy y Santiago del Estero. Lo mismo ocurre con el servicio personal que continuó en Córdoba, Catamarca y La Rioja hacia fines del siglo XVII (Farberman y Boixadós, 2006; Bixio, 2009; Conti, 2019).

12. Los diaguitas-calchaquíes habían sido desnaturalizados durante la última campaña (1659-1666) y los tobas y mocovíes, provenientes del Chaco, eran quienes se encontraban mayormente en tierras privadas (Boixadós, 2002: 30). 
13. Estas encomiendas, estrechamente vinculadas, estaban compuestas por población desnaturalizada desde el oeste catamarqueño luego del Gran alzamiento de 1630 (García, 2018).

14. Aunque la posesión de encomiendas por tres generaciones y el fraccionamiento de las mismas estaba prohibido por las Leyes de Indias, González Rodríguez (1984) explica que por las dificultades de fundar ciudades en el Tucumán colonial y lograr el efectivo control de los indígenas se permitieron ciertas excepciones, como la dejación del cuarto. Para más información sobre los orígenes de las encomiendas y su fragmentación en un tronco y cuarto, remito a Lorandi y Sosa Miatello (1991); Quiroga (2012) y García (2018).

15. AHPC. Esc. 2da, Leg. 4, Exp. 26, f. 9 v. especies y en trabajo con equivalencia monetaria- dominaba en los Pueblos, el servicio personal continuaba vigente, con mayor fuerza en los grupos más pequeños y desestructurados asentados en las casas de sus amos. En estos grupos se presentaban las mayores arbitrariedades y violaciones a las normativas, ya que al no cobrar tributo el beneficio del encomendero dependía de cuanto explotara a los indígenas, realizando todo tipo de ejercicios coercitivos para aumentar sus ingresos.

Entonces, a pesar de las intenciones de Alfaro, la autoridad de los encomenderos no logró ser mellada y las prácticas infrajudiciales siguieron vigentes. El poder de los encomenderos "no sólo se aplicó a nivel correccional -terreno del padre y del encomendero- sino que también se extendió a situaciones donde hubiera cabido la intervención de la justicia penal" (González Navarro y Grana, 2013: 8). No obstante, las sociedades indígenas elaboraron determinadas estrategias para revelar estos abusos y hacer escuchar sus reclamos. Como veremos, tanto las visitas como los litigios basados en legislación que los favorecía fueron la principal vía de denuncia.

\section{"Lo aporreó y maltrató por haber ido a pedir su justicia". La violencia en el juicio por la estancia de Guaco}

La estancia denominada Guaco, en el valle de Sanagasta -aproximadamente $30 \mathrm{~km}$ al norte de la ciudad de La Rioja-, funcionó como lugar de reducción de dos encomiendas indígenas hacia fines de siglo XVII. Don Isidro de Villafañe y Guzmán, dueño de la propiedad, instaló allí a los miembros de su encomienda de andalgalá, malfin -parcialidades mayoritarias-, yuctava, nogolma y asapates alrededor de $1650 .{ }^{13}$ El cuarto de los tributarios de la parcialidad de andalgalá, que también residía formalmente en Guaco, estaba encomendado en segunda vida a doña Pascuala de Tapia y Artaza, vecina de Londres. ${ }^{14}$

Durante el periodo analizado -fines de siglo XVII- el Pueblo de Guaco constituye un caso intermedio dentro del panorama riojano planteado por Boixadós (2002). Aunque los indígenas son inicialmente asentados en tierras privadas tienen espacio para construir sus viviendas, cultivar y poseer ganado lo cual les permite llevar un estilo de vida comunitaria. Podemos pensar en Guaco como una encomienda-pueblo en términos de Boixadós.

Cuando Villafañe fallece en 1674, la encomienda de malfín, andalgalá y anexos se asigna a don Gil Gregorio Bazán de Pedraza, quien se rehúsa a mudar a los indígenas de Guaco. Entonces, entre 1674 y 1690 se desarrolla un juicio por la estancia, ya que los herederos de Villafañe la reclamaban como propia y no podían hacer usufructo de ella mientras estuvieran los indígenas. Aprovechando el conflicto, en 1680 Francisco Gualcusa, mandón de la encomienda, concurre personalmente a la Audiencia de La Plata de los Charcas.

Pide retornar a su antiguo natural, que dice ser Andalgalá, argumentando que en Guaco no tienen agua y pasan frío y hambre ya que la producción es escasa. Denuncia que Villafañe, su antiguo encomendero, los ha "ido mudando para obligarnos a servicios que no debemos y servirse de nuestras mujeres e hijos y hacernos malos tratamientos contra lo dispuesto por las ordenanzas". Al finalizar su petición, el mandón pide que la Audiencia "no consienta que el encomendero [Bazán de Pedraza] nos obligue a servicios personales ni a más de lo que disponen las ordenanzas ni nos maltrate".${ }^{15}$. La expresión malos tratamientos y abusos es frecuente en las fuentes coloniales y encerraba todo tipo 
de ejercicios coercitivos violentos y despiadados, accionar que contradecía la normativa protectora de los indígenas.

La Audiencia le otorga una Real Provisión que prohíbe los excesos de los encomenderos y determina que se les asigne un lugar de asentamiento cómodo, a determinar por la justicia local (García, 2018). En julio de 1680 al volver a La Rioja, Gualcusa intima la Provisión al teniente de gobernador don Manuel de Villafañe, quien realiza un interrogatorio a los caciques e indios principales donde se les pregunta qué lugar escogían para vivir. Según las fuentes, casi todos los indígenas comparten el deseo de Gualcusa y escogen Andalgalá. ${ }^{16}$

Viendo la puesta en marcha de la Provisión, Bazán presenta reiteradas peticiones en el cabildo riojano. La mudanza de los indios a Andalgalá era sumamente perjudicial: en Catamarca estarían más alejados y no podría ejercer un control directo. Aliados con su encomendero, los caciques don Gerónimo Pibala y don Juan Aballay piden permanecer en Guaco.

En 1681 Bazán viaja a Córdoba y eleva sus reclamos al Gobernador don Fernando de Mendoza Mate de Luna. Le pide un mandamiento para poder recoger a sus indios, afirmando que desde la intervención de Gualcusa le perdieron el respeto y fueron desamparando Guaco. Solicita la ayuda de don Ignacio Callavi "para que con su gente los saque de dondequiera que estuviesen y los traiga a su pueblo y reducción de Guaco" ${ }^{17}$ Callavi era el cacique del Pueblo de Pipanaco, encomienda de la jurisdicción de Londres de Domingo de Pedraza, hermano de Bazán.

El Gobernador demanda oír a ambas partes antes de tomar una decisión, por lo que Francisco Gualcusa, acompañado por un séquito de indios, viaja a Córdoba. El protector de naturales Ignacio de Loyola actúa en nombre de Gualcusa para hacer su defensa y desagravio. Comienza su escrito sosteniendo que las condiciones ambientales y materiales de la estancia de Guaco hacen muy difícil la vida allí, lo cual habría motivado el viaje del mandón a la Audiencia de La Plata. Sostiene que cuenta con el apoyo de la mayoría de los indios de la encomienda y que todos piden regresar a Andalgalá. Para finalizar, dice que el Gobernador no debe

$$
\begin{aligned}
& \text { atender a los fines injustos que pretende el dicho su encomendero viendo solo } \\
& \text { sus conveniencias teniendo obligación precisa de ver la de sus encomendados } \\
& \text { según la Ley del Rey nuestro señor que tanto los favorece pues no atendiendo } \\
& \text { a esta obligación lo aporreó y maltrató de palabras por haber ido a la Real } \\
& \text { Audiencia a pedir su justicia }{ }^{18}
\end{aligned}
$$

Aquí aparece claramente el uso de la violencia como amedrentamiento y castigo. Apelar a la justicia real, a través de los cabildos y audiencias, era un derecho que les correspondía por su condición de súbditos de la corona. Cuando coincidían los intereses de los indígenas y de los encomenderos, estos apoyaban sus demandas y participaban como testigos o financiando los costos de la justicia. No obstante, cuando los reclamos eran en contra de los encomenderos o los perjudicaban, los indígenas podían sufrir represalias, castigos y todo tipo de presiones para que abandonen la empresa (Bixio y González Navarro, 2009: 387).

Gualcusa, a través del protector de naturales, está inculpando a Bazán de haberlo violentado física y verbalmente. Además, lo acusa de velar solamente por sus intereses y no por el bienestar de sus encomendados, infringiendo de
16. AHPC. Esc. 2da, Leg. 4, Exp. 26, f. 14 r.

17. AHPC. Esc. 2da, Leg. 4, Exp. 26. f. 33 r.

18. AHPC. Esc. 2da, Leg. 4, Exp. 26, f. $46 \mathrm{v}$. 
19. Este cacique merece una mención aparte pues fue un personaje muy poderoso que ejerció la violencia contra sus indígenas y los de otras encomiendas, a tal punto que poseía una cárcel y un cepo con siete agujeros en su casa en Andalgalá (Conti, 2019: 134). Callavi sabía leer y escribir y ostentaba el título de sargento mayor de los indios de la jurisdicción de Londres debido a su participación militar en las conquistas del valle Calchaquí y del Chaco a favor de los españoles. Contaba con el apoyo de los cabildantes de San Fernando, el teniente de gobernador y algunos párrocos locales, quienes justificaban su accionar violento diciendo que lo hacía 'con celo y piedad cristiana' (Conti, 2019).

20. AHPC. Esc. 2da, Leg. 4, Exp. 26, fs. $49 \mathrm{r}$ a $53 \mathrm{v}$. ambas formas la legislación real. Él se defiende afirmando que nunca le puso una mano encima y asevera que Gualcusa es un inquietador.

El Gobernador Mate de Luna ordena que los indios se reduzcan en Guaco hasta que él o alguien de su gobierno vaya a La Rioja a determinar qué es lo más conveniente; mientras tanto los indígenas deben permanecer en la estancia sin que nadie los embarace o inquiete en su posesión. Además, autoriza a don Ignacio Callavi, ${ }^{19}$ cacique de Pipanaco, a recoger a los indios que estuviesen en Andalgalá, ${ }^{20}$ lo cual hace entre febrero y marzo de 1682 . Al respecto, contamos con el testimonio de Juan Apotaan, indio del cuarto de andalgalá, quien denuncia años más tarde ante el visitador Luján de Vargas los castigos que recibió de Callavi por seguir a Gualcusa. Veamos su declaración:

Juan indio de la encomienda de doña Francisca Bustos de Villegas paresco ante Vuestra Señoria y digo que me querello civil y criminalmente contra don Ignacio Callavi cassique de Pipanaco y refiriendo el casso digo que abiendoseme señalado por pueblo el paraje de Andalgalá por real provicion que se gano en la ciudad de La Plata de pedimento de Francisco Baleusamandon de los yndios me fuy al dicho pueblo de Andalgalá con mi muger e hijos sin mas caussa que le pudiere mover llebado de su intrepides y mal natural me cogió ynjustamente y a mano y me dio una buelta de asotes dejandome por muerto y luego me quito el cavello y me hecho quitandome mis hijos solo por complacer al encomendero del pueblo y estancia de Guaco y por sus particulares fines causa que perdi mis sembrados y toda mi pobreza [216 r.] que hasta el dia de oy he estado andando padeciendo sin tener ante quien pedir este agravio manifiesto por el mucho poder y sequito que tiene con dos los del cavildo desta ciudad [...] se a de servir de mirar esta caussa y exparcir su celo cristiano y castigar al dicho don Ignacio mandandome pagar mi sangre derramada y los cavellos quitados como si fuesse yndio rebelde quando he sido tan leal serbidor de Su Magestad como es notorio (en Castro Olañeta, 2017: 244).

Esta declaración muestra que Juan y su familia querían permanecer en Andalgalá y sufrieron un fuerte castigo por ello. También pone en evidencia el poder que ostentaba el encomendero de Guaco para lograr el retorno de los indígenas a La Rioja, y los contactos e influencias que tenía Callavi dentro de la sociedad hispano-criolla. Juan tuvo que esperar más de diez años la llegada de un funcionario externo a la Gobernación, como el oidor Luján de Vargas, para poder denunciar estos hechos y sortear las redes de poder locales que protegían a los encomenderos y a los caciques aliados.

En su defensa ante el visitador, Callavi recuerda este hecho y confiesa haberle dado doce azotes y cortado los cabellos a Juan "por no querer hir dicho yndio al pueblo de Guaco por horden del señor gobernador [...] que sobre aberle mandado si fuesse y no obedesidole se bio obligado a asotarle por la facultad que se le da por dichas hordenes" (en Castro Olañeta, 2017: 232). Las órdenes del Gobernador no mencionan el uso de la violencia, por lo que es una atribución propia. Sobre el uso del cepo, dice que no lo recuerda.

Tanto el corte de cabellos como los azotes fueron castigos muy frecuentes hacia la población indígena (Torres Arancivia, 2016). Con el corte del cabello -trasquilar- se busca estigmatizar a la víctima, ya que tener el cabello largo poseía un valor simbólico muy fuerte para las poblaciones nativas (Bixio, 2003: 456). Se cree que en el mundo andino el peinado, el pelo y los tocados eran marcas de identidad que diferenciaban a los ayllus o comunidades de parentesco (Torres 
Arancivia, 2016: 554). ${ }^{21}$ Con los azotes se busca logar dolor físico, dejando al sujeto incapacitado por varios días según la cantidad y profundidad de los cortes. Pero además del dolor, Covarrubias afirma en su diccionario del siglo XVI que el castigo de los azotes trae infamia (Torres Arancivia, 2016: 538).

Estos castigos tienen en común que ambos marcan al infractor porque se graban en su cuerpo las huellas del poder, de la autoridad (Bixio, 2003). La ofensa, el haber traspasado los límites, se hace visible para todos desacreditando al sujeto públicamente, en el caso de los azotes a veces con marcas que llevará de por vida. La importancia simbólica de estos dos castigos se aprecia al final del testimonio de Juan, donde pide que Callavi pague "por la sangre derramada y los cabellos quitados como si fuera un indio rebelde" (en Castro Olañeta, 2017: 244).

Comparando los discursos, Juan denuncia más cosas de las que confiesa Callavi. Mientras que este afirma haberle cortado el cabello y dado solamente doce azotes, Juan sostiene que casi lo deja muerto, que le quitó a sus hijos y por todo ello perdió sus cultivos y cayó en la pobreza. ${ }^{22}$ Para fortalecer su denuncia, Juan presenta como testigos a los indios Miguel, Pedro y Juan de la encomienda de Domingo Pedraza -cuyo cacique era Callavi. Por cuestiones de espacio, citaré solo el testimonio de Juan:

este testigo vio como don Ignacio Callavi gobernador deste declarante cogió agora siete u ocho años al dicho yndio Juan y lo colgo desnudo en un arbol en las cassas que tiene en el fuerte de Andalgala y le dio por sus manos muchos asotes y le quito el cavello y lo puso en el sepo por dos dias y no saver la causa (en Castro Olañeta, 2017: 245).

Los testimonios son muy interesantes. En primer lugar, aportan nueva información sobre cómo fue ejecutado dicho castigo, el cual se nos presenta como más violento aún: para azotarlo con sus propias manos, Callavi colgó a Juan Apotaan de un árbol y lo desnudó. Luego, lo dejó dos días en un cepo, probablemente el que tenía en su casa. Esta acción va en contra de la orden del Gobernador que Callavi esgrime como justificación, ya que la orden buscaba que los indios regresen a Guaco lo antes posible, mientras que Callavi hirió a Juan y lo retuvo un mínimo de dos días en condiciones tortuosas. En segundo lugar, los testimonios muestran la solidaridad entre indios de distintas encomiendas. Miguel, Pedro y Juan se animaron a testificar contra su cacique, denunciando los actos violentos que este cometió contra un indígena externo a su grupo.

En la visita de Luján de Vargas, junto al de Juan, hay numerosos testimonios de indígenas denunciando a Callavi, quien los golpeaba cotidianamente, los obligaba a trabajar en su beneficio y los trasladaba contra su voluntad del Pueblo de indios a las cercanías del fuerte de Andalgalá donde residía. ${ }^{23}$ Luego de abrir un proceso contra él, Luján de Vargas lo encuentra culpable de haber abusado de su poder y competencias y lo castiga con un año de destierro en el presidio de Esteco (Conti, 2019: 139). Recordemos que, según las Ordenanzas de Alfaro, los alcaldes de indios y no los caciques podían ejercer justicia dentro de las reducciones.

En 1683 los indígenas liderados por Gualcusa consiguen un auto del Gobernador que avala su traslado a Andalgalá y se mudan allí. Sin embargo, al año siguiente el encomendero y los caciques Pibala y Aballay obtienen una sentencia favorable para ser nuevamente reducidos en Guaco. Para que
21. Caillavet señala que para las sociedades indígenas el cabello tiene una poderosa connotación masculina, postulando un paralelismo entre la noción de honor que se podía desprender de la ostentación de la barba por parte de un hispano con la idea de ser un hombre con la cabellera larga en los Andes (en Torres Arancivia, 2016: 556).

22. El haberle quitado a sus hijos parece un hecho significativo. Los ingamana denuncian ante Luján de Vargas que Callavi les robaba sus mujeres, sacándolas de sus hogares y obligándolas a tejer e hilar con el fin de beneficiarse del trabajo de las indias de otra encomienda (Conti, 2019). Este puede ser un caso similar. Juan dice que lo echó quitándole sus hijos, quizás para hacerlos trabajar para él por un tiempo determinado.

23. Para una descripción y análisis del proceso contra Callavi, remito a Conti (2019). 
24. En este apartado nos referiremos solamente a los indígenas encomendados a Don Gil Gregorio Bazán de Pedraza. Los miembros del cuarto de andalgalá, encomienda de Francisca Bustos de Villegas que también residían en Guaco no presentan quejas de su encomendera o de Bazán en su rol de administrador.
25. La presencia nociva de los mayordomos fue constatada para muchos de los pueblos de indios y encomiendas riojanas. Boixadós refiere que además de supervisar el trabajo de los indígenas en la chacra de comunidad, las mitas y la producción de hilados, cumplían funciones de policía controlando que no huyeran, asistieran a misa, no se embriagaran, etc. (Boixadós, 2002: 33). esto suceda, Bazán de Pedraza se compromete a pagar el valor de las tierras a los herederos de Villafañe. A partir de este momento, Guaco no es más una estancia privada de la familia Villafañe sino que adopta la forma de Pueblo de indios (García, en prensa). En las fuentes se relata el retorno a Guaco de 1685 como un destierro forzado donde perdieron los ganados y sementeras que habían construido en Andalgalá (García, 2018), lo cual puede entenderse como otra forma de violencia.

\section{"Cogiéndolo de los cabellos y dándole de puñetes". Castigos cotidianos dentro del Pueblo de indios desde la visita de Luján de Vargas}

Antonio Martínez Luján de Vargas, oidor de la Audiencia de Charcas, llega a la Gobernación del Tucumán hacia fines de 1692 con el objetivo de realizar una visita de desagravio a la población indígena (Palomeque, 2000). La visita se realizó en respuesta a las numerosas denuncias de religiosos -incluso de gobernadores- sobre las modalidades ilegales que habían adoptado las relaciones interétnicas (Bixio, 2007: 61). Buscaba conocer la situación de la población indígena, observar el cumplimiento de la normativa vigente -las referidas Ordenanzas de Alfaro- y solucionar los problemas que surgieren.

El arribo del oidor permitió a los grupos indígenas enunciar acusaciones contra distintos actores -encomenderos, pobleros, caciques abusivos- que no aparecen en otra documentación. Varios autores han resaltado como llamativas las declaraciones uniformes y coordinadas por el servicio personal, la falta de doctrina, la privación de pueblos y tierras para sembrar, los malos tratamientos, etc. (Palomeque, 2000; Boixadós y Zanolli, 2003; Farberman y Boixadós, 2006; Bixio 2007, 2009;). Los reclamos pueden pensarse como estrategias de resistencia colectivamente ideadas para evidenciar el accionar arbitrario e ilegal de ciertos actores coloniales (Bixio y González Navarro, 2009). Esto se aprecia en las declaraciones de los indios de Guaco, quienes denuncian colectivamente a su encomendero. ${ }^{24}$

Como advierte Boixadós (2003), hay que analizar críticamente los alegatos de ambas partes, tratando de reconstruir la matriz de las relaciones que dieron sentido a las quejas y los estereotipos hispanos e indígenas. La Visita fue un espacio de lucha -cuyos testimonios están permeados de temor, resentimiento y desconfianza mutua- donde se esperaba que el visitador pudiera dirimir y sancionar un nuevo código de relacionamiento (Boixadós, 2003: 25).

El cacique Pedro Aballay, anteriormente aliado con el encomendero, denuncia que Bazán instaló un poblero que vive con su madre en el Pueblo de Guaco, el cual "apremia a los muchachos que no tienen diez y ocho años a que le sirvan y así lo hacen estos contra su voluntad" (en Boixadós y Zanolli, 2003: 159). Si bien no lo aclara, creemos que el apremiar incluye modos violentos y de coacción física. ${ }^{25}$ También sostiene que el encomendero lo aporreó en tres ocasiones "por querer enviar a dicho cacique con carretas y no haber querido ir" (en Boixadós y Zanolli, 2003: 159). Este hecho es confirmado por los testimonios del resto de los indígenas, añadiendo algunos más detalles. Por ejemplo, Juan Uti declara que

vio que el encomendero aporreó en una ocasión al cacique Don Pedro en el dicho pueblo [Guaco] cogiéndolo de los cabellos y dándole de puñetes y ha oído decir que en esta ciudad [La Rioja] lo ha aporreado en otras ocasiones al 
mismo curaca quien le contó que por no haber querido ir picando una carreta a Córdoba lo aporreó (en Boixadós y Zanolli, 2003: 160).

Prosiguiendo con la Visita, Tomás y Miguel denuncian que:

el dicho encomendero ahora seis meses en la siega de trigo aporreó a Santiago y a este que declara por defender al dicho Santiago su yerno y este declarante es Miguel al cual y a su yerno les dio en el cuerpo muchos golpes con un palo, y el dicho Tomás ha oído decir de este mal tratamiento a los dicho dos indios (en Boixadós y Zanolli, 2003: 161).

Otro castigo que se enuncia es el que recibió Isabel, mujer de Cristóbal, a quien el encomendero "aporreó en su rancho y le tiró de los cabellos, dándole golpes con las manos o con un palo", según relatos distintos, por ocasión de que su hijo no había ido a trabajar (en Boixadós y Zanolli, 2003: 160-161). Además, Isabel sostiene que el accionar de Bazán se caracteriza por "de ordinario maltratar a las dichas indias de palabra" (en Boixadós y Zanolli, 2003: 165). Su esposo Cristóbal denuncia que "ahora seis años en esta ciudad el dicho su encomendero lo cogió de los cabellos y lo derribó al suelo y le dio de puñetes y esto dijeron les hace por ser un hombre de mala condición" (en Boixadós y Zanolli, 2003: 163). En este caso, el castigo se explicaría no por una falta de Cristóbal sino por el mal temperamento y la esencia de Bazán. El indio Miguel es otra víctima de Bazán, quien lo aporreó:

por estar conchabado por su voluntad con Don Juan Herrera seis años acudiéndole con cinco pesos de tributo cada año y el pasado dice que su encomendero topándolo en la calle de la Compañía le dio de puñetes y lo arrastró de los cabellos por el suelo y lo metió a la casa de Don Juan Bazán y estándole maltratando vino Don Gerónimo Gaete y lo quitó (en Boixadós y Zanolli, 2003: 163).

Es importante reparar que los castigos que relatan los indígenas no los obtuvieron por cometer delitos o faltas graves como estipulaba la normativa. Por el contrario, la mayoría de ellos fueron castigados por oponerse al encomendero o negarse a trabajar para él, abusando de la potestad de su cargo. En ninguno de estos casos hubiese correspondido la intervención y el arbitrio de la justicia local, pero tampoco el uso de la violencia.

En su desagravio, Bazán de Pedraza responde a estas acusaciones negándolas, mitigándolas o justificándose. Veamos algunos ejemplos. Sobre haber aporreado al cacique Aballay, no hace referencia al apremio de ir con las carretas a Córdoba pero afirma que después de aconsejarlo buenamente "lo ha reprendido con alguna aspereza [porque se] daba a la embriagadez y al vicio, siendo un mal ejemplo para el resto de sus sujetos" (en Boixadós y Zanolli, 2003: 170). Menciona que con los indios del común participa en juntas y borracheras que desafían las costumbres y políticas cristianas, en vez de corregir a los demás. Aquí está haciendo referencia al extendido estereotipo hispano sobre el indio andino como ocioso, borracho e idólatra ${ }^{26}$ que justificaría el correctivo ante los ojos del visitador. Sobre los golpes a Santiago y Miguel relata que sus caballos habían entrado y arruinado la sementera de trigo de comunidad. Mandó a su hijo que los llevara al corral,

[...] y llevandolos le salieron los susodichos yerno y suegro embriagados y le quitaron los caballos con libertad y demasia según volvió mi hijo [a donde estaba yo] llorando por haberle perdido el respeto y queridolo aporrear por
26. La acusación de borracho era sumamente grave porque estaba asociada al pecado. "El incurrir en el vicio del alcohol era caer en la tentación de un deseo hedonista, alejarse de la armonía, de la proporción y de la virtud. Pero, el borracho es más pecaminoso porque su razonamiento está nublado, alterado, y así -más próximo a la condición del orate o del animal- es más proclive a cometer una serie de actos aberrantes y violentos" (Torres Arancivia, 2016: 504). Para el autor, el imaginario hispano asocia la persona borracha con la ociosidad y los actos demoniacos -robos, homicidios, incestos, promiscuidad exacerbada, etc. Se fue formando una imagen totalmente estereotipada del indio andino como vago, pusilánime, sucio, cristiano nuevo, propenso a la gentilidad y alcohólico (Torres Arancivia, 2016: 506) que se generalizó y reprodujo en los discursos de españoles de la Gobernación (Boixadós, 2002). 
27. Todas las citas textuales de este párrafo fueron tomadas de Boixadós y Zanolli (2003: 170-171).
28. Sobre la forma en que se realiza este pago, los indígenas declaran que "les hace sembrar el dicho encomendero diciéndoles que es chacra de comunidad dándoles para ello las semillas y los bueyes y que acabada la dicha sementera se saca el diezmo y de lo demás se pone la mitad para el dicho encomendero y la otra mitad para ellos y que de esta mitad puesta para dichos indios reparte el dicho encomendero a las indias por almudes en paga del trabajo que tienen de los hilados que se les reparte y que si sobra algo se lo hace traer a esta ciudad el dicho encomendero diciendo que de su procedido ha de hacer ornamentos para dicha capilla y que no les da nada y se queda con todo" (en Boixadós y Zanolli, 2003: 163-164).

29. En cambio, los indios pertenecientes al cuarto de Andalgalá, cuyo administrador era Bazán declaran que pagaban cinco pesos anuales (Boixadós y Zanolli, 2003: 172). cuya causa me dispuse a ir al rancho de dichos indios a reprenderlos de palabra y ellos se me opusieron con desacato encarando para mi el dicho Miguel con el puño cerrado amagándome y vista la acción y conteniéndome en medio de ella le di dos rempujones de que cayó en tierra que fue fácil por estar embriagado y al dicho su yerno Santiago le hice dos amagues con la mano del puño cerrado de que resultó el sosegarse de ellos y no pasó otra cosa (en Boixadós y Zanolli, 2003: 171).

Bazán admite haberse enfrentado a estos indios; no obstante, según él solo hubo dos empujones y un amague con el puño cerrado, mientras que ellos denuncian que fueron golpeados muchas veces con un palo. Sobre Isabel, dirá que su hijo es el encargado de enseñar a rezar a los demás indios de la encomienda, pero por ausentarse

[...] lo hice traer y corrigiéndolo por faltar al rezado se me fue de las manos y fui en persona a casa de su madre quien se me opuso con libertad desatenta y entonces le di un rempujón con un bordoncillo que tenía en las manos por haber encarado contra mí sin darle golpe alguno ni haberme apeado de la mula (en Boixadós y Zanolli, 2003: 171).

Nuevamente, el relato de los indígenas describe una situación mucho más violenta de la que el encomendero admite. Notamos que esto también ocurrió con las denuncias a Callavi. Analizando el desagravio de Bazán, la tendencia es negar que los castigos y ejercicios coercitivos hayan sido cometidos o atenuarlos: "lo reprendí con alguna aspereza", "le hice dos amagues", "le di un rempujón y se cayó por estar embriagado". Asimismo, remarca la necesidad del castigo físico en base a las características de la población: "fue para que se refrene en tan desordenado vicio y perjudicial", "se me opusieron con desacato"; o por su finalidad: "me han perdido el respeto", "para corrección de sus idolatrías e infidelidad".27

En ocasiones, el encomendero busca hacerle entender al oidor la imposibilidad del cumplimiento de la leyes y ordenanzas por las características de la población nativa, justificando el uso de la violencia: “y si el encomendero no tiene poder para corregirlos [...] que medio podrá tomar para poder descargar la real consciencia y la suya cuando curas ni justicias son bastantes a corregirlos" (en Boixadós y Zanolli, 2003: 170). Sin embargo, no obstante la ilegalidad de muchas de sus prácticas Bazán admite la ley general y asegura respetarla (Bixio, 2007). Por ejemplo, sobre tener poblero en el Pueblo, prohibido por las Ordenanzas de Alfaro, adjudica su falta de cumplimiento a que: "dicha prohibición no ha llegado sino ahora a mi noticia por no habérnosla advertido los gobernadores y visitadores generales" (en Boixadós y Zanolli, 2003: 169).

Además de las referidas, en la visita los indios denuncian otras prácticas que, si bien no involucran castigos físicos, son violentas y dan cuenta de la situación desigual de poder y de explotación. El encomendero cobraba sus tributos solamente de los cultivos de la chacara de comunidad, ${ }^{28}$ peculiaridad que no se repite en el resto de las encomiendas o pueblos de indios riojanos (Boixadós, 2002). ${ }^{29}$ Según las Ordenanzas de Alfaro, la chacra de comunidad debía ser trabajada con el aporte de bueyes, semillas y aperos del encomendero y la mano de obra indígena, y el producto era dividido en partes iguales entre encomenderos y encomendados. Es decir que al encomendero le correspondía la mitad de lo cultivado en chacra de comunidad, además del pago de los cinco pesos de tributo. No obstante, los indígenas de la encomienda de Bazán 
de Pedraza parecen haber llegado a un tipo de acuerdo o negociación para saldar el tributo de esa forma.

Podríamos pensar que es un tributo en especie, donde los indígenas controlan los tiempos de la producción. Aunque esto parece beneficioso, el mismo no está monetizado, no habiendo una equivalencia entre los cinco pesos de tributo que tendrían que pagar según las Ordenanzas y lo que el encomendero se lleva. Además, los indígenas denuncian que Bazán se apropiaba de la totalidad de los cultivos, mostrando que estaba incumpliendo su acuerdo. Con la mitad que les correspondía a ellos pagaba a las indias por sus tareas de hilado y tejido, que hacían presionadas por el poblero y su madre (Boixadós y Zanolli, 2003: 164). Si sobraba algo de su mitad se llevaba los cultivos para venderlos y comprar ganado y ornamentos para la capilla en nombre de los indios, quienes reclaman que nunca les llegaba.

Esta modalidad convertía a las mujeres en una fuerza de trabajo valiosa cuya explotación no tenía ningún costo para Bazán. Las demandas de hilados se combinaban con otras tareas que las indias debían cumplir, como servicios domésticos en la casa de su encomendero. $\mathrm{Al}$ respecto, todos los interrogados declaran que Bazán sacó del Pueblo de Guaco a tres chinas nombradas Bartola, Petrona y Bartolina teniéndolas en el servicio de su casa en La Rioja (Boixadós y Zanolli, 2003: 163).

A pesar de que estaba prohibido, los niños y muchachos menores de dieciocho años también servían a Bazán, apremiados por el poblero. Sumado a esto, las acusaciones del cacique Aballay, de haber sido golpeado por no querer viajar a Córdoba, y la de Miguel, a quien Bazán "le dio de puñetes y lo arrastró de los cabellos por el suelo" (en Boixadós y Zanolli, 2003: 171) por estar conchabado con otro vecino, muestran que Bazán buscaba acaparar para sí todo el trabajo de los indios e indias de Guaco. En estas acciones vemos que el servicio personal no estaba totalmente superado. Sin embargo, estas prácticas no pueden asimilarse completamente al sistema de servicio personal reglamentado por Abreu en sus Ordenanzas más de cien años atrás (Bixio, 2009: 18).

En el caso analizado, paralelamente a estas prácticas ilegales que remiten al sistema de explotación por servicio personal, hay cierto cumplimiento de las Ordenanzas de Alfaro (Boixadós, 2002; García, en prensa). Hacia fines del siglo XVII los malfines, andalgalás y anexos instalados en Guaco tienen tierras propias, separadas de las de su encomendero, en las que se encuentran sus viviendas, chacras de comunidad y sementeras individuales, corrales con ganados y una capilla que construyeron con su trabajo. ${ }^{30}$ El tributo es en especies -trigo de la chacra de comunidad- o en moneda en el caso del cuarto de andalgalá. Además, poseen un sistema de autoridades indígenas -caciques y mandones. Las fuentes también mencionan que hay un indio fiscal y otro que cumple el rol de alcalde, insinuando la presencia de un cabildo indígena pero no hay datos sobre si este funcionaba realmente.

Esta complejidad ya fue advertida por Boixadós, quien afirma que en muchas encomiendas y Pueblos riojanos coexistían formas de pago del tributo que remitían al sistema alfariano con prestaciones de servicio personal al encomendero -adoptando este sentido cuando los trabajos indígenas no se pagaban en tiempo y forma- (Boixadós, 2002: 42). Bixio (2009) llega a la misma conclusión al examinar las declaraciones de los indígenas y encomenderos cordobeses en la Visita de Luján, evidenciando la existencia de un sistema híbrido donde se combinan los marcos normativos.
30. Para una descripción más detallada de los espacios materiales del pueblo de Guaco, ver García (en prensa). 
31. Todas las citas del párrafo fueron tomadas del AHPC. Esc. 2da, Leg. 4, Exp. 26, fs. 2 a 7.
Para cerrar este apartado, es importante reparar en que el contexto social colonial no permite dudar de los testimonios indígenas, aunque es evidente que estuvieron formulados estratégicamente (Boixadós, 2003). El visitador aceptó estos testimonios como verdaderos y no las complicadas justificaciones de Bazán, a quien encuentra culpable de muchas faltas y le impone una multa de 70 pesos de a ocho reales, la quinta más elevada de La Rioja. Al final de la sentencia, le ordena que cumpla las cédulas de su Majestad y ordenanzas de la provincia "especialmente en el tratamiento de los indios sin castigarles por ningún modo pues para el exceso que cometan tiene prevenidos remedios el derecho" (en Boixadós y Zanolli, 2003: 174).

\section{"Sólo es para idolatría y vivir en sus anchuras". Percepciones hispano-criollas sobre las prácticas indígenas}

El caso presentado es un buen ejemplo para ver de qué manera los significados se construyen en un intercambio de miradas en el que los actores, posicionados en un entramado social, interpretan y adjudican un sentido a las prácticas del otro y de ellos mismos. La apuesta de este apartado es captar el imaginario hispano-criollo que subyace a los ejercicios coercitivos recibidos por los indígenas, pensando qué es lo que teme o quiere impedir el estamento dominante.

Según Mantecón Movellán (2002), todo comportamiento reprensible reclama ser controlado porque presenta las siguientes características. Primero, altera la paz pública. Segundo, se considera un comportamiento desviado dentro de la comunidad. Tercero, esta desviación constituye un mal ejemplo para los demás miembros del grupo (Manetcón Movellán, 2002: 73). Estos rasgos aparecen claramente en el discurso de Bazán, tanto en las presentaciones judiciales como en el desagravio en la Visita.

Hemos visto que Bazán obstruye las iniciativas indígenas de retorno hacia sus antiguos territorios a través de la violencia. ¿Cuáles son sus motivaciones para esto? A lo largo de su argumentación, la antigua rebeldía de los malfines y andalgalás es la razón principal por la cual no deberían regresar a la jurisdicción de Londres. El encomendero se opone al traslado a Andalgalá afirmando que sus encomendados "fueron indios alzados, como los de Calchaquí, y se redujeron a fuerza de armas". Añade que estando en su natural "han perdido la obediencia a su majestad" profiriendo insultos y cometiendo muertes y hostilidades. Por lo tanto, advierte a la justicia el daño de volver a poblar los valles, ya que "fueron desnaturalizados por conveniencia y paz pública". ${ }^{31}$ Además, agrega que en dichos parajes no habrá cura que los pueda asistir en la enseñanza católica, por lo tanto pronostica que volverán a sus antiguas idolatrías.

Al enfatizar el riesgo de que al regresar a los territorios catamarqueños se vuelvan a alzar, el encomendero está reproduciendo el imaginario social. Los actores hispanos que participaron en las guerras de conquista del siglo XVII elaboraron una narrativa sobre la peligrosidad de las poblaciones indígenas y la continua amenaza que representaban para el ordenamiento colonial (Rodríguez, 2017). Este relato, que incluía solamente la voz de los vencedores, sirvió para justificar las entradas a los territorios indígenas, apropiarse de sus tierras y mano de obra y reclamar beneficios a la corona -mercedes de tierras y encomiendas-, entre otros. 
No obstante, también reflejaba el pánico real que tenían los vecinos españoles ante la posibilidad de que los indígenas se volvieran contra ellos. ${ }^{32}$ Esto es así porque tuvieron que lucharlas y financiarlas con gran perjuicio para sus vidas, familias, patrimonios y negocios. Tanto en las Actas del Cabildo de distintas ciudades de la Gobernación, como en cartas de los gobernadores y religiosos la guerra con nativos se menciona siempre como posibilidad, virtualidad y riesgo (Bixio y González Navarro, 2009; Rodríguez, 2017). Entonces, la posibilidad -remota- de un nuevo alzamiento general que desequilibrara el control logrado sobre los indígenas justificaba todo tipo de vejaciones y castigos.

Bazán interpreta los reclamos de Gualcusa y sus seguidores como una estrategia para huir del control colonial, vivir a sus anchuras y escapar de la sujeción cristiana. Busca impedir su traslado aludiendo al peligro que supondría la mudanza para toda la sociedad. Es decir, los indígenas debían ser reducidos en Guaco en beneficio de la paz y el orden colectivo, cumpliendo la primera característica que reseña Mantecón Movellán (2002). También afirma que "se debe temer que si mis encomendados regresan pronto se les sumarán indios forajidos, delincuentes y huidos con deseos de recomenzar las guerras". ${ }^{33}$ Aquí aparece otro de los rasgos, que es el peligro de contagio y del mal ejemplo. Recordemos que Bazán no recibió castigo ni reprimenda por haber maltratado a Gualcusa cuando fue a la Audiencia. Desde esta lógica, el castigo y los malos tratos a los indígenas ayudaban a anular un peligro virtual para el mantenimiento del orden establecido, por lo tanto no eran sancionados por los funcionarios coloniales.

Por supuesto, Bazán también tiene motivaciones personales para oponerse a la mudanza, que oculta o deja en un segundo plano en sus peticiones. Ve la actitud de Gualcusa como un desafío a su autoridad de encomendero y sabe que de asentarse en Andalgalá le será más difícil controlar a los indígenas y que trabajen para él. Sus ganancias ilegales, como el apropiarse de todo el producto de la chacara de comunidad y del trabajo no pago de sus encomendados, seguramente se verían perjudicadas por la larga distancia y la imposibilidad de acudir personalmente a apremiarlos de palabra y maltratarlos físicamente.

En su desagravio en la Visita, se aprecia el mismo estilo de argumentación y construcción de los comportamientos sancionables, apareciendo con más claridad la segunda y tercer característica de Mantecón Movellán (2002). Utiliza los castigos físicos para reprimir los comportamientos desviados dentro del Pueblo de indios y que suponen un mal ejemplo ya que atentan contra las costumbres cristianas, como las borracheras o el haber faltado al rezo.

Algunos castigos que Bazán reconoce haber impartido fueron porque los indígenas "se le opusieron con libertad desatenta", con "desacato" o "actuaron con libertad y demasia" (en Boixadós y Zanolli, 2003: 171). Bazán justifica la violencia, apremios y los malos tratamientos por la altivez con que los indígenas le contestaban, la falta de respeto y soberbia, debiendo castigarlos para volverlos indios domésticos. Esta era una situación común: "toda vez que los indígenas se dirigían a ellos de forma impropia, no reconociendo su superioridad, los encomenderos y mayordomos reaccionaban con violencia" (Boixadós, 2002: 47).

El hecho de que los indígenas actuaran con libertad, en contra de sus intereses y negándose a cumplir con ciertas obligaciones de trabajo, era motivo de alerta, de temor: representaba una autonomía que debía ser castigada. Este miedo,
32. Llama la atención que treinta años después de sofocado el levantamiento de Bohórquez, no habiendo datos directos ni indirectos de oposición colectiva que adoptara la forma de una resistencia armada, las ‘Guerras Calchaquíes' siguieran tan presentes en el recuerdo de los encomenderos.

33. AHPC. Esc. 2da, Leg. 4, Exp. 26, fs. 2 a 7 . 
como afirma Boixadós (2002: 48), probablemente se remontaba a su pasado como indios guerreros, rebeldes y difíciles de someter.

\section{Reflexiones finales}

Hemos analizado dos tipos de fuentes donde aparecen distintos ejercicios coercitivos dentro de un Pueblo de indios riojano. En primer lugar, relevamos los castigos y amedrentamientos que sufrieron el mandón Francisco Gualcusa y Juan Apotaan en el juicio por las tierras de Guaco. Luego, se examinaron las denuncias ante Luján de Vargas, mostrando cómo la violencia, los apremios y los malos tratamientos estaban insertos en su vida cotidiana, jugando un rol central en las relaciones interétnicas. Si bien trabajos previos habían estudiado esta problemática en la Visita, el aporte de este artículo radica en incorporar el juicio. Analizando conjuntamente la documentación se logra un abordaje más completo de la problemática, ampliando la escala de estudio y triangulando la información, como mostró el caso de Callavi.

Haciendo una síntesis, los indígenas radicados en el Pueblo de Guaco fueron castigados por: acudir a la justicia y participar en pleitos -Francisco Gualcusa-, demorarse en acatar una orden -Juan Apotaan-, rehusarse a trabajar para el encomendero en carácter de servicio personal -Don Juan Aballay, muchachos menores de dieciocho años-, conchabarse con otro vecino -Miguel-, arruinar la sementera con sus ganados -Santiago y Miguel- y oponerse al encomendero por encubrir a un hijo -Isabel-, o simplemente porque el encomendero es un hombre de mala condición -Cristóbal. Sumados a estos castigos puntuales los indígenas denuncian malos tratamientos cotidianos, apremios y maltratos de palabra.

Viendo esto, se aprecia que varios castigos eran injustificados y totalmente abusivos -como los recibidos por ir a la justicia, concertarse con otro español o negarse a servir al encomendero- ya que no habían cometido falta alguna. Tomando como marco normativo las Ordenanzas de Alfaro observamos que los castigos fueron ilegítimos, ya que ni Bazán ni el cacique Callavi tenían las competencias para realizar castigos corporales hacia los indígenas de Guaco. Es por ello que ambos fueron condenados por Luján de Vargas.

En cuanto al encomendero, se nota cierta ambigüedad punitiva ya que, como referimos anteriormente, podía sancionar malos comportamientos, como parecerían ser los de Isabel, Santiago y Miguel, pero no castigar a los indígenas "arrastrándolos de los cabellos y golpeándolos con un palo" (en Boixadós y Zanolli, 2003: 161) como refiere la acusación. Estos actos, que evidencian un alto nivel de violencia interpersonal, fueron realizados según su voluntad y parecer, aprovechando su posición y el límite difuso entre la sanción permitida de un mal comportamiento y una falta o delito. Al administrar castigos corporales dentro del Pueblo, se aprecia una atribución de poder y funciones que contradecía explícitamente la legislación indiana y las Ordenanzas de la provincia. Esta atribución se generaliza en el estamento encomendero y se vuelve abusiva, hecho que los visitadores no logran limitar luego de que se impusiera tempranamente en la Gobernación con el aval silencioso de las elites locales.

Retomamos el concepto de infrajusticia para caracterizar a este espacio donde ciertos agentes coloniales, desde posiciones de poder y apartándose de la normativa y caminos institucionales, deciden qué comportamientos son tolerables y cuáles no, sancionando a estos últimos (Mantecón Movellán, 2002). Esto lo 
hacen respaldados por prácticas, valores, prejuicios e imaginarios comunes, algunos de ellos mencionados en este artículo, como el discurso de peligrosidad de los indígenas o su supuesta vagancia natural y tendencia hacia la borrachera.

Se llega a la conclusión de que el ejercicio de la violencia por parte del encomendero tenía tres claros objetivos. Primero, buscaba garantizar que los indígenas cumplieran con sus obligaciones laborales, a la vez que las maximizaba haciéndolos trabajar contra su voluntad cuando fuera posible para aumentar sus ganancias. Esto debe ser enmarcado dentro de un contexto donde ciertas prácticas de servicio personal seguían vigentes. El caso de los muchachos forzados por el poblero a servir a Bazán, a pesar de estar prohibido, es un buen ejemplo. De esto se desprende que los castigos tenían una dimensión económica.

Segundo, a través de la violencia se sancionaban los comportamientos desviados o intolerables, que desafiaban el orden establecido y los intereses de los actores que detentaban el poder. Aquí aparece otra dimensión de los ejercicios coercitivos, la punitivita, por la cual se pretendía lograr un férreo control de la población indígena. Esta dimensión está estrechamente vinculada con la función pedagógica y el carácter ejemplificador de los mismos, considerados correctivos para encauzar acciones desviadas.

Tercero, con la violencia se buscaba el ajuste de los nativos al sistema colonial y su aceptación de la posición de dominados (Bixio, 2007; González Navarro y Grana, 2013). Los amedrentamientos, apremios, malos tratos y castigos corporales disuadían a los indígenas de orquestar un nuevo levantamiento y, a la larga, socavaban su autonomía. Los castigos que recibe Gualcusa por inquietador, o los indígenas que fueron castigados por actuar con libertad $y$ demasia son testimonios de esto. Se desprende una nueva dimensión: la simbólica. Especialmente con los castigos que dejan marcas, como los azotes o el trasquilar, se inscribe en el cuerpo del sujeto un atributo profundamente desacreditador que actualizará la falta cometida ante sí mismo y los demás, ubicándolo en una posición de inferioridad social y moral (Bixio, 2003: 457).

Para hacer frente a estas prácticas abusivas y violentas los indígenas llevaron a cabo distintas estrategias. Una fue denunciar la ilegalidad de los castigos recibidos ante funcionarios externos a la Gobernación del Tucumán, lo que les permitía eludir las redes de poderes locales que encubrían a los encomenderos. Entre ellos se encuentran el visitador Luján de Vargas o los oidores de la Audiencia de Charcas, a quien Gualcusa presenta sus reclamos. En la Visita, otra estrategia fue coordinar los testimonios para unificar las versiones y que las acusaciones contra Bazán y Callavi tengan mayor solidez, logrando sanciones favorables. Para ello, fue necesario sostener y activar lazos de solidaridad entre los indígenas de Guaco y también entre los miembros de distintas encomiendas, tal fue el caso de los indios de Pipanaco que declararon a favor de Juan Apotaan. Finalmente, los malfines y andalgalás desarrollan una estrategia que, a largo plazo, les va a permitir liberarse del estrecho control de su encomendero riojano. Tanto por vías legales como a través de huidas orquestadas por las autoridades étnicas, en el siglo siguiente consiguen modificar su lugar de reducción volviendo a su antiguo natural en Andalgalá. Esto se logra luego del fallecimiento del encomendero Gil Gregorio Bazán de Pedraza, quien -como vimos- trató de impedir su mudanza incansablemente, a través de todos los medios que tuvo a su alcance como: presentaciones ante la justicia, amedrentamiento de sus encomendados y uso de violencia física y verbal. 


\section{Agradecimientos}

A las Dras. Dolores Estruch y Elisa Caselli por la invitación a formar parte de este Dossier. A la Dra. Laura Quiroga, mi directora, por su atenta lectura y sugerencias. A los evaluadores de este artículo por sus valiosas recomendaciones. 


\section{Q Fuentes documentales citadas}

Archivo Histórico de la Provincia de Córdoba (AHPC). Escribanía 2da, Legajo 4, Expediente 26. "Don Gil Gregorio Bazán de Pedraza pide encomienda de los indios del Guaco - título de dichas tierras del Guaco".

\section{Q Bibliografía citada}

"Agüero, A. (2011). El testimonio procesal y la administración de justicia penal en la periferia de la Monarquía Católica, siglos XVII y XVIII. Acta Histriae 19: 43-60.

》 Aranda Mendiáz, M. (2006). La protección de los indígenas en la Recopilación de Antonio de León Pinelo y en la Recopilación de Leyes de Indias de 1680. Revista de la Inquisición 12: 277-294.

» Araya, A. (2006). El castigo físico: el cuerpo como representación de la persona, un capítulo en la historia de la occidentalización de América, siglos XVI-XVIII. Historia 39 (2): 349-367.

»Angeli, S. (2014). “'Una existencia etérea': el concepto de Estado colonial y sus críticas recientes” en Dell'Elicine, E.; Francisco, H., Miceli, P. y A. Morin (orgs.); Clientelismo, parentesco y cultura jurisdiccional en las sociedades precapitalistas: 121-132. Los Polvorines, Universidad Nacional de General Sarmiento.

》 Bixio, B. (2003). Políticas de la justicia criminal interétnica en Córdoba del Tucumán (siglos XVI y XVII). Anuario de estudios americanos 60: (2): 441-462.

" Bixio, B. (2007). La visita del oidor Luxan de Vargas a la jurisdicción de Córdoba del Tucumán (1692-1693): práctica de la justicia y disputa de valores. Revista Española de Antropología Americana 37 (2): 61-79.

" Bixio, B. (2009). Categorías en disputa: el servicio personal según la visita de Luxan de Vargas al Tucumán colonial Memoria Académica. Segundas Jornadas Nacionales de Historia Social. La Falda, Córdoba 13 al 15 de mayo. Disponible en Internet http://www. memoria.fahce.unlp.edu.ar/trab_eventos/ev.9683/ev.9683.pdf Consultada el: 11 de mayo de 2020.

» Bixio, B. y C. González Navarro (2009). Dominación, resistencia y autonomía en el extremo sur del Virreinato del Perú (siglos XVI y XVII). Diálogos 13 (2): 371-399.

»Boixadós R. (2002). "Los pueblos de indios de La Rioja colonial. Tierra, trabajo y tributo en el siglo XVII" en Farberman J. \& Gil Montero R. (eds.); Los pueblos de indios del Tucumán colonial: pervivencia y desestructuración: 15-57. Bernal, Universidad Nacional de Quilmes.

» Boixadós, R. (2003). “La visita de Luján de Vargas a las encomiendas riojanas (1693): comentarios, notas y lecturas posibles" en Boixadós R. y C. Zanolli; La visita de Luján de 
Vargas a las encomiendas de La Rioja y Jujuy (1693-1694). Estudios preliminares y fuentes: 21-40. Bernal, Universidad Nacional de Quilmes.

"Boixadós, R. y C. Zanolli (2003). La visita de Luján de Vargas a las encomiendas de La Rioja y Jujuy. Estudios preliminares y fuentes. Bernal, Universidad Nacional de Quilmes.

" Castro Olañeta, I. (2017). La Visita del oidor Antonio Martínez Luján de Vargas a las encomiendas de Catamarca, Santiago del Estero y Salta (Gobernación del Tucumán, 16931694), Córdoba, Programa de Historia Regional Andina (PHRA, CIFFyH-UNC)/ Ferreyra Editor.

»Cebreiros-Álvarez, E. (2004). "La condición jurídica de los indios y el derecho común: un ejemplo del "favor protectionis" en Condorelli, O. (ed); Panta rei: Studi dedicati a Manlio Bellomo: 469-489. Roma, II Cigno Edizioni.

"Clavero, B. (1986). Tantas personas como estados. Madrid, Tecnos.

"Clavero, B. (1990). "Delito y pecado. Noción y escala de transgresiones" en Tomas y Valiente, F.; Clavero, B.; Hespanha, A. M.; Bermejo, J. L.; Gacto, E. y C. Álvarez Alonso; Sexo barroco y otras transgresiones premodernas: 57-89. Madrid, Alianza Editorial.

" Conti, S. (2019). “Los pueblos de indios de Catamarca a través de la visita de Luján de Vargas. Tierra, tributo y trabajo". Tesis de licenciatura para el grado en Historia. Buenos Aires, Facultad de Filosofía y Letras, Universidad de Buenos Aires.

»Farberman, J.y R. Boixadós (2006). Sociedades indígenas y encomienda en el Tucumán colonial. Un análisis comparado de la visita de Luján de Vargas. Revista de Indias 66 (238): 601-628.

» Foucault, M. (1996). “Undécima lección. 17 de marzo de 1976. Del poder de soberanía al poder sobre la vida" en Foucault, M.; Genealogía del Racismo: 193-214. La Plata, Ed. Altamira.

" García, M. (2018). Buscando las voces nativas en la justicia colonial: Las autoridades de malfines y andalgalas y su reproducción comunitaria (La Rioja, 1674-1693). Andes 29: (2). Disponible en Internet: http://www.icsoh.unsa.edu.ar/icsoh/wp-content/ uploads/2019/05/7-andes-2018-29-2-garcia.pdf. Consultada el: 21 de abril de 2020.

» García, M. (en prensa). Habitar un pueblo de indios: La reducción de Guaco a través de fuentes judiciales (La Rioja, 1685). Diálogo Andino.

» González Navarro, C. y R. Grana (2013). Conflictividad y usos sociales en la elite encomendera de Córdoba del Tucumán (Virreinato del Perú- 1573-1700). Nuevo Mundo Mundos Nuevos. Disponible en internet: http://journals.openedition.org/ nuevomundo/64801. Consultado el: 20 de mayo de 2020.

» González Rodríguez, L. (1984). La encomienda en Tucumán. Sevilla, Diputación de Sevilla, Servicio de Archivo y Publicaciones.

» Hespanha, A. (2011). El estatuto jurídico de la mujer en el derecho común clásico. Revista jurídica de la Universidad Autónoma de Madrid 4: 71-87.

" Levaggi, A. (1975). Las penas de muerte y aflicción ene el derecho indiano rioplatense. Revista de Historia del Derecho 3: 81-164.

»Lorandi, A. M. (1988). El servicio personal agente de desestructuración en el Tucumán colonial. Revista Andina 6 (1): 135-173.

"Lorandi, A. M. y S. Sosa Miatello (1991). El precio de la libertad. Desnaturalización y traslado de indios rebeldes en el siglo XVII. Memoria Americana. Cuadernos de etnohistoria 1: 7-28.

»Ots Capdequí, J. (1941). El estado español en las Indias. México, El colegio de México. 
» Mantecón Movellán, T. (2002). El peso de la infrajudicialidad en el control del crimen durante la edad moderna. Estudis 28: 43:75.

»Palomeque, S. (200o). “El mundo indígena. Siglos XVI-XVIII” en Tandeter, E. (coord.); Nueva Historia Argentina II: 87-144. Buenos Aires, Editorial Sudamericana.

»Quiroga, L. (2012). Las granjerías de la tierra: actores y escenarios del conflicto colonial en el valle de Londres (gobernación del Tucumán, 1607-1611). Surandino Monográfico 2 (2). Disponible en Internet: http://revistascientificas.filo.uba.ar/index.php/surandino/ article/view/5916. Consultada el: 26 de marzo de 2020.

»Quarleri, L. (2018). Castigos físicos y control de los cuerpos. Mujeres guaraníes, trabajo y poder colonial. Temas americanistas 40: 239-264.

» Rodríguez, L. (2017). Efectos imprevistos de las desnaturalizaciones del Valle Calchaquí (noroeste argentino). El “doble asentamiento" como estrategia de resistencia. Chungará 49 (4): 601-612.

» Tomás y Valiente, F. (1969). El derecho penal de la monarquía absoluta: (siglos XVI-XVIIXVII). Madrid, Tecnos.

» Torres Arancivia, E. (2016). La violencia en los Andes. Historia de un concepto, siglos XVIXVII. Lima, Instituto Riva-Agüero/ PUCU. 